\title{
Адювантна терапия при рецидивиращата респираторна папиломатоза в детската възраст
}

\author{
Спиридон Тодоров \\ УНГ-кЛиника при УМБАЛ "ЦІарица Йоанна", ИСУЛ - ЕАД - София
}

\begin{abstract}
The article covers the contemporary methods for adjuvant therapy for juvenile-onset laryngeal papillomatosis. The results from the application of alpha-interferon, acyclovir, indol-3-carbinol, ribavirin and photodynamic therapy have been discussed.
\end{abstract}

\section{Резюме}

В статията се прави обзор на сьвременните методи за адювантна терапия на ювенилната ларингеална папиломатоза Обсьждат се резултатите от приложснието на алфа-интерферон, ацикловир, индол-3-карбинол, ретиноиди, рибавирин и фотодинамичната терапия.
$\mathrm{P}$ ецидивиращата респираторна папиломатоза е заболяване с вирусна етиология, причинено от Human papillomavirus (HPV).

Заболяването може да се прояви във всяка възраст, но характерно за него е бимодалното му възрастово разпределение. Първият пик се наблюдава при деца до 5 години, а вторият - при възрастни над 30 години. Освен времето на поява РРП показва и значителни различия в клиниката, протичането, прогнозата и лечението, което дава основание заболяването да се раздели на две основи форми: ювенилна папиломатоза и папиломатоза при възрастните.

Ювенилната форма протича по-агресивно от тази при възрастните (34). При това колкото по-малко е детето, толкова агресивността на заболяването е по-голяма. Проучванията на Armstrong et al. (1999) (5) сочат, че при деца, на които диагнозата е поставена под 3годишна възраст, два пъти по-често се наблюдава едновременно засягане на две и повече области в ларинкса. При децата под 3 години се наблюдава и по-често разпространение на папиломите извън ларинкса (30).

Засега няма самостоятелно лечение или комбинация от различни лечебни методи, които да гарантират пълното излекуване на РРІІ. Хирургичното лечение остава главният метод за лечение на РРП. Но при не по-малко от $10 \%$ от болните се явява необходимост от прилагане и на друг вид лечение (9). Критериите за включване на адювантна терапия са: необходимост от повече от 4 хирургични процедури годишно, бързо нарастване на папиломите с обструкция на дихателните пътища и дистално разпространение на папиломите (10). Решението дали да се приложи допълнително лечение трябва да се вземе след строга преценка за ползата и 
страничните ефекти на съответния лечебен метод (33). Съвременните адювантни лечебни методи на РРП включват: alpha-interferon, acyclovir, indol-3carbinol, retinoic acid, ribavirin, cidofovir и фотодинамична терапия.

Алфа-интерферонът е най-широко прилаганият препарат за адювантна терапия на ларингеалната папиломатоза $(9,16)$. Интимният механизъм на действието на интерферона не е съвсем ясен, но е установено, че след приложение на интерферон нивата на протеинкиназа P1 и ендонуклеаза се повишават пет до десет пьти, което води до потискане синтезатата на вирусните протеини и разкъсване на вирусната РНК. Освен това интерферонът има доказано цитостатично и цитокинетично въздействие (т.е. има способност да модулира клетъчния цикъл и скоростта на клетъчното деление). На трето място интерфероните са мощни активатори на NK-клетките и макрофагите, които след това могат да разрушат клетките на тумора или инфектираните с вирус клетки.

През 1981 год. Haglund et al. (15) първи съобщиха за намаление размера на папиломите при всички седем пациенти, лекувани с алфа-интерферон. Малко по-късно McCabe \& Clark (23) съобщават, че от лекуваните от тях 19 пациенти с интерферон 17 са се подобрили, включително и двама с белодробна локализация. Благоприятни резултати при $75 \%$ до $86 \%$ от болните с интерфероновото лечение съобщават по-късно и редица други автори (6, $18,22,27,36)$. В една серия от 123 болни Healy et al. (16) сравняват резултатите от лечението само с лазер и комбинация от лазер и интерферон. Те намират статистически достоверно подобрение, изразено в забавен растеж на папиломите, само при болните лекувани с интерферон, но отбелязват, че това подобрение е било само през първите шест месеца. До същите изводи стигат и Leventhal et al. $(20,21)$, като лекуват 33 деца само с лазер и 33 деца с лазер и интерферон.

Незадоволителният ефект от приложението на алфа-интерферон може да се дължи и на недостатъчната дозировка и продължителност на лечението. Mullouly et al. (27) съобщават, че въпреки липсата на резултат при 6 от осемте болни, получавали интерферон в стандартна дозировка, 5 от тях са получили пълна или частична ремисия с двукратно по-голяма доза (18 MIU седмично), прилагана в течение на три години. За необходимостта от продължително приложение на интерферона съобщават и други автори $(7,13)$.

Правени са проучвания и за взаимовръзката между резултатите от интерфероновото лечение и типа HPV, изолиран от папиломите. Gerein et al. (14) намират, че пациенти с HPV (11) показват много по-слаб резултат от лечението с интерферон (14\%), отколкото тези с HPV (6) (64\%). Обратно на тях, Нурмухаметов и сътр. (1) при 40 деца с РРП не установяват връзка между типа HPV и ефективността на интерфероновото лечение.

Walther \& Herberhold (35) лекуват девет пациенти c ларинготрахеална папиломатоза чрез локално аплициране на алфа-2а-интерферон $\left(\right.$ Roferon $^{\circledR}$ ) след лазерна ексцизия на папиломите. Те считат, че локалното приложение на интерферона дава много добри резултати, като се избягват страничните ефекти при системното му приложение.

Според Derkay \& Faust (10) страничните ефекти при лечението с алфа-интерферон могат да се разделят на две категории: остри реакции (повишена температура, грипоподобни симптоми, втрисане, миалгия, главоболие) и хронични реакции (изоставане в растежа на детето, повишение нивото на трансаминазите, гастроинтестинални оплаквания, левкопения и тромбоцитопения). Наблюдавани са още обриви, кожен сърбеж и алопеция $(6,8)$. Въпреки наличието на странични явления, последните много рядко стават причина за прекъсване на лечението с интерферон.

Acyclovir е друго противовирусно средство, приложено за пръв път от Aguado et al. (1991) (3) при три деца с РРП с много добър резултат. Ацикловирьт е аналог на тимидин-киназата, която е закодирана във веригата на някои вируси (Herpes simplex и Varicella-Zoster virus). Монофосфатната му форма се превръща в активна ди- и трифосфатна форма от целуларните ензими, като процесът на фосфорилиране е около един милион пъти побърз при вирусната тимидин-киназа, отколкото при човешката. Като действа конкурентно антагонистично, ацикловирът разгражда веригата на ДНК и прекъсва репликацията на вируса. Но тъй като при човешкия папиломен вирус не е доказана тимидин-киназа, то и действието на ацикловир върху РРП е неясно и не винаги е сигурно (25). Лечението е по-успешно, когато е налице коинфекция на HPV с други вируси като Herpes Simplex Virus, Cytomegalovirus и Epstein-Barre Virus (29). Endres et al. (12) лекуват с Acyclovir 6 деца с ларингеална папиломатоза в продьлжение на 6 месеца, като при 5 от тях отчитат значително подобрение. Kiroglu et al. (19) лекуват 12 болни - възрастни и деца - с Acyclovir per os и установяват подобрение при 9 болни и липса на ефект при 3 болни. Те считат, че ацикловирът има място като допълнително лечение на РРП поради липсата на странични явления и лесното му приложение през устата. 
Индол-3-карбинолът (I3C) е химическо съединение, което се намира в зелето и другите кръстоцветни зеленчуци. През 1993 год. Newfield et al. (28) първи съобщиха за връзката между I3С и естрогенния метаболизьм, който е фактор за канцерогенезата в хормонално свързаните тъкани. Експериментите показват, че I3C унищожава пролиферативния ефект на естрадиола в клетъчни култури и редуцира развитието на ларингеални папиломи при имунокомпрометирани мишки. Rosen et al. (31) лекуват 18 пациенти с I3С и ги проследяват за срок от средно 14.6 месеца. Резултатите сочат, че една трета от болните са с пълна ремисия, една трета - с частично подобрение и една трета - без ефект от лечението. Индол-3-карбинольт се прилага през устата в дози 3 - 5 мг/кг под названието Nutrin-3. В последно време последният бе заместен от ди-индол-метан (DIM), който представлява две молекули I3C, свързани с карбонова връзка, и се предлага като хранителна добавка под името Phytosorb-DIM (във вид на капсули и сироп). Клиничният опит от приложението на I3C все още е недостатъчен и не позволява категорични изводи, но сборни сатистики сочат, че от 78 пациенти при 40 е регистрирано подобрение, а при 38 лечението е било без ефект (5). Предимствата на лечението с I3C са пълната безвредност на препарата, лесният начин на приложение (през устата), което повишава неговия къмплайънс в сравнение с този на интерферона и значително по-ниската му цена (2). Известно е, че витамин А и неговите деривати - ретиноидите - имат модулиращ ефект върху клетъчната диференциация и пролиферация. Т. напр. в дихателните пътища излишъкът от витамин А потиска епителната диференциация и може да доведе до метаплазия на цилиндричния епител, докато недостигът на витамин А може да причини хиперкератинизация и метаплазия на плоския епител (17). Alberts et al. (4) са лекували 5 болни с 13cis-retinoic acid $(0.5-2.0 \mathrm{mg} / \mathrm{kg} /$ day per os) поради неефективност на приложеното преди това лечение с лазер. При двама от болните се е получила пълна ремисия, а при един - частична ремисия за срок до две години. Eicher et al. (11) съобщават, че 24-годишен пациент с малигнена дегенерация на РРП е получил драматично подобрение след приложение на $1 \mathrm{mg} / \mathrm{kg} /$ day 13 -cis-retinoic acid. Клинично проучване в The Medical College of Georgia c $1 \mathrm{mg} / \mathrm{kg} /$ day trans-retinol приложен при ювенилна форма на РРП е показало сигнификантно подобрение при някои пациенти, въпреки че резултатите не са още категорични (8).

Рибавирин е нуклеозиден аналог с широк антивирусен спектьр, който се използва най-често за лечение на синцитиал-вирусните пневмонии при децата. McGlenen et al. (24) са лекували 8 пациенти с дългогодишна ларингеална папиломатоза с рибавирин през устата в доза $23 \mathrm{mg} / \mathrm{kg} /$ day. Всички болни са показали значително подобрение, проявено с увеличаване на интервала между отделните хирургически интервенции. Morrison et al. (26) съобщават за едно дете с трахеобронхиално разпространение на папиломите, което е третирано всеки две седмици с $\mathrm{CO}_{2}$-лазер без особен ефект, на което са приложили рибавирин през устата $(5 \mathrm{mg} / \mathrm{kg})$ и във вид на аерозол в продължение на два месеца. През този период броят на хирургическите интервенции е намалял значително и не са регистрирани никакви странични ефекти.

В последните години нараства интересът към локалното приложение на Cidofovir (Vistide ${ }^{\circledR}$ ) след хирургичното отстраняване на ларингеалните папиломи. Цидофовир е ацикличен нуклеозид, активен срещу редица DNA-вируси, който се прилага обичайно при цитомегаловирусния ретинит у пациенти c HIV инфекция. Резултатите на Shirly \& Wiatrak (32) обаче сочат, че Cidofovir е само отчасти активен при децата. От 11 деца с агресивна ларингеална папиломатоза само 3 деца са получили голямо подобрение, 2 са били с частично подобрение и при 6 деца лечението е било без ефект.

Фотодинамичната терапия бе въведена като допълнение на класическата лазерна терапия с цел да се избегнат неприятните последствия от последната (синехии, цикатрикси и др.). На болния се инжектира венозно фотосензибилизиращо вещество - dihematoporphyrin aether (DHE), което се натрупва два пъти повече в неопластичните, отколкото в нормалните тъкани. При облъчване с лазерна светлина с дължина на вълната $630 \mathrm{~nm}$ се предизвиква фототоксичен процес, който разрушава само туморните тъкани, без да се увреждат околните здрави тъкани. Един неприятен страничен ефект на този вид лечение е продължителната чуствителност на пациентите към светлината, която трае 2 до 8 месеца. За да се избегне този страничен ефект, в последно време се използва meso-tetra(hydroxyphenyl) chlorine $\left(\right.$ Foscan $\left.^{\circledR}\right)$, чието фотосенсибилизиращо действие трае само около 2 седмици, а избирателното му натрупване в папиломите е 10 пъти по-голямо в сравнение с нормалните тькани. Тези резултати сочат, че въпреки липсата на остатъчни синехии и сраствания след PDT, последната не е най-оптималният метод за лечение на РРП.

Предлаганите алтернативни методи имат своето място при лечението на РРП, но засега хирургичното лечение остава главен метод за лечение на това заболяване. 


\section{Литература:}

1. Нурмухамстов РХ, Онуфриева ЕК, Солдатский ЮЛ, Бродский МЮ. Влияние типов вируса папилломы человека на течение ювенильного респираторного папилломатоза и еффективность интерферонотерапии у детей. Вестн оторинолар 2000; 2.

2. Солдатский Л, Киселев ВИ, Онуфрисва ЕКр Стеклов АМ, Щепин НВ, Стрыгина ЮВ, Гаспарян СФ, Погосова ИЕ. Анализ еффективности противорецидивной терапии ювенильного респираторного папилломатоза при помощи индинола. Вестн Оторинолар 2006; 1 : $46-48$.

3. Aguado DL, Pinero BP, Betancor L, Banales CE. Acyclovir in the treatment of laryngeal papillomatosis. Int J Ped Otorhinolaryngol 1991; 21 L 269-74.

4. Alberts DS, Coulthard SW, Meyskens FL. Regression of aggressive laryngeal papillomatosis with 13-cis-retinoic acid (accutane). J Biol Response Mod 1986; 5: 124-8.

5. Armstrong LR, Derkay CS, Reeves WC. Initial results from the National Registry for Juvenile-onset recurrent papillomatosis Arch otolaryngol Head Neck Surg 1999; 125: 743-48.

6. Avidano MA, Singleton GT. Adjuvant drug strategies in the treatment of recurrent respiratory papillomatosis. Otolaryngol Head Neck Surg 1995; 112: 187-202

7. Benjamin BN, Gatenby PA, Kitchen R, Harrison H, Cameron K, Basten A. Alpha-interferon (Wellferon) as an adjunct to standard surgical therapy in the management of recurrent respiratory papillomatosis. Ann Otol Rhinol Laryngol 1988; 87: 376-80.

8. Bent JP, Porubsky ES. Recurrent respiratory papillomatosis. Insights in Otolaryngology 1993; 8: 1-8.

9. Derkay CS. Task force on recurrent respiratory papillomatosis. A preliminary report. Arch Otolaryngol Head Neck Surg 1995; 121: 1386 $-91$

10. Derkay CS, Faust RA. Recurrent respiratory papillomatosis. In: Cummings Otolaryngology Head \& Neck surgery.-4 Ed.-Philadelphia: Elsvier Mosby, 2005; vol 4: 4370-86.

11. Eicher SA, Taylor-Cooley LD, Donovan DT. Isotretinoin therapy for recurrent respiratory papillomatosis. Arch Otolaryngol Head Neck Surg 1994: 120: 405-9.

12. Endres DR, Bauman NM, Burke D, Smith RJ. Acyclovir in the treatment of recurrent respiratory papillomatosis. Ann Otol Rhinol Laryngol 1994; 103: 301-5.

13. Gerein V, Lodemann E, Bell G, vonllberg C, Kornhuber B. Results of long-term leucocyte interferon (alpha IFN) therapy using an individually determined dose schedule in recurrent laryngeal papillomatosis. Klin Pediatr 1987; 199: 224-9.

14. Gerein V, Rastorguev E, Gerein J, Jecker P, Pfister H. Use of interferonalpha in recurrent respiratory papillomatosis: 20-year foolow-up. Ann Otol Rhinol Laryngol 2005;114:463-71.

15. Haglund S, Lundquist $\mathrm{P}$, Cantell $\mathrm{K}$, Strander $\mathrm{H}$. Interferon therapy in juvenile laryngeal papillomatosis Arch Otolaryngol 1981; 107: 327-32.

16. Healy GB, Gelber RD, Trowbridge AL, et al. Treatment of recurrent respiratory papillomatosis with human leucocyte interferon. Results of a multicenter randomized clinical trial N Engl J Med 1988; 319: 401-7.

17. Huang C, Ma WY, Dawson MI, Rincon M, Flavell RA, Dong Z. Blocking activator protein-1 activity, but not activating retinoic acid response element, is required for the antitumor effect of retinoic acid. Proc Natl Acad Sci USA 1997; 94: 5826- 30.

18. Kashima H, Leventhal B, Clark K, Cohen S, Dedo H, Donovan D, Fcaron B, Gardiner L, Goepfert H, Lusk R. Interferon-alpha-N1 (Wellferon) in juvenile-onset recurrent respiratory papillomatosis: resuts of a randomized study in twelve collaborative institutions. Laryngoscope 1988; 98: 334-40.
19. Kiroglu M, Cetik F, Soylu F, Abedi A, Aydogan B et al. Acyclovir in the tratment of recurrent respiratory papillomatosis: a preliminary report. Am J Otolaryngol. 1994; 15: 212-14

20. Leventhal BG, Kashima HK, Mounts P, Thurmond L, Chapman S, Buckley S, Wold D. Long-term response of recurrent respiratory papollomatosis to treatment with lymphblastoid interferon alfa-n1. Papilloma study group. N Engl J Med 1991; 325: 613-7.

21. Leventhal BG, Kashima HK, Weck PW, Mounts P, Whisnant JK, Clark KL, Cohen S, Dedo HH, Donovan DJ, Fearon BW. Randomized surgical adjuvant trial of interferon alfa-n1 in recurrent papillomatosis. Arch Otolaryngol Head Neck Surg 1988; 114: 1163-9.

22. Lusk RP, McCabe BF, Mixon JH. Three-year experience of trating recurrent respiratory papilloma with interferon. Ann Otol Rhinol Laryngol 1987; 96: 158-62

23. McCabe BF,Klark KF. Interferon and laryngeal papillomas: the Iowa experience. Ann Otol Rhinol Laryngol 1983; 92: 2-7.

24. McGlennen RC, Adams GL, Lewis CM, Faras AJ, Ostrow RS. Pilot trial of ribavirin for the treatment of laryngeal papillomatosis. Head Neck 1993; 15: 504-512.

25. Morrison GA, Evans JN. Juvenile respiratory papillomatosis: acyclovir reassessed. Int J Pediatr Otorhinolaryngol 1993; 26: 193-7.

26. Morrison GA, Kotecha B, Evans JN. Ribavirin treatment for juvenile respiratory papillomatosis. J Laryngol Otol. 1993; 107: 423-6.

27. Mullooly VM, Abramson AL, Steinberg BM, Horowitz MS. Clinical effects of alpha-interferon dose variation on laryngeal papilloma. Laryngoscope 1988; 98:1324-29.

28. Newfield L, Goldsmith A, Bradlow L, Auborn K. Estrogen metabolism and human papillomavirus-induced tumors of the larynx: chemo-prophylaxis with indole-3-carbinol. Anticancer Res 1993; 13: 337-342.

29. Pou AM, Rimell FM, Jordan JA, Shoemaker DL, Johnson JT, Barua P Post JC, Ehrlich GD. Adult respiratory papillomatosis: human Papillomavirus type and viral coinfections as predictors of prognosis. Ann Otol Rhinol Laryngol 1995; 104: 758-62.

30. Rimell FL, Shoemaker DL, Pou AM, Jordan JA, Post JC, Ehrlich GD. Pediatric respiratory papillomatosis: prognostic role of viral typing and cofactors. Laryngoscope 1997; 107: 915-18.

31. Rosen CA, Woodson GE, Thomson JW, Hengesteg AP, Bradlow HL. Preliminary results of the use of indol-3-carbinol for recurrent respiratory papillomatosis. Otolaryngol Head Neck Surg. 1988; 118: 810815

32. Rosen CA, Woodson GE, Thomson JW, Hengesteg AP, Bradlow HL. Preliminary results of the use of indol-3-carbinol for recurrent respiratory papillomatosis. Otolaryngol Head Neck Surg. 1988; 118: 810815.

33. Shykhon M, Kuo M, Pearman K. Recurrent respiratory papillomatosis. Clin Otolaryngol, 2002; 27: 237-243.

34. Silverman DA, Pitman MJ. Current diagnostic and management trends for recurrent respiratory papillomatosis. Curr Opin Otolaryngol Head Neck Surg 2004; 12: 532-7.

35. Walther EK, Herberhold C. Treatment of laryngotracheal papillomatosis with combined use of laser surgery and intralesional administration of alpha-interferon (Roferon). Laryngorhinootology 1993; 72: 485-91.

36. Zenner HP, Kley W, Claros B, Lahas Z, Lobe LP,Pavelka R, Plath P, Ribari O, Xiethammer D, Hirche H. Recombinant Interferon-alpha-2c in laryngeal papillomatosis: preliminary results of a prospective multicentre trial. Oncology 1985; Suppl 1; 42: 15-18.

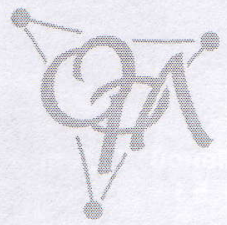

